\title{
Projetos Didáticos de Gênero, Escrita Praxiológica e Desenvolvimento Profissional de Professores: um estudo de caso
}

\author{
Genre Didactical Projects, Praxeological Writing and \\ Professional Development of Teachers: A case study
}

Anderson Carnin*

Resumo: Este artigo apresenta uma análise do desenvolvimento profissional de uma professora participante de um curso de formação continuada pautado no trabalho com projetos didáticos de gênero (GUIMARÃES; KERSCH, 2012, 2014). Concebendo a noção de gênero de texto como instrumento psicológico (MACHADO; LOUSADA, 2010) e focalizando a dimensão praxiológica da escrita docente, o artigo analisa como a apropriação de tal conceito pela docente permite que sejam desvelados índices de seu desenvolvimento profissional a partir da análise de sua escrita. Como pressuposto teórico assume-se a perspectiva do Interacionismo Sociodiscursivo (BRONCKART, 2006, 2013; FRIEDRICH, 2012), da transposição didática (CHEVALLARD, 1985) e da didática da escrita (REUTER, 2013), a fim de analisar os modos de apropriação do conceito de gênero de texto (em uma perspectiva didática) e sua representação na escrita praxiológica do professor. Os resultados sugerem que o desenvolvimento profissional está intimamente ligado à transformação do conceito de gênero de texto em instrumento psicológico por parte da professora participante da pesquisa.

Palavras-chave: projetos didáticos de gênero; escrita; desenvolvimento profissional.

\footnotetext{
* Doutor em Linguística Aplicada pela Universidade do Vale do Rio dos Sinos (2015). Professor do Programa de Pós-Graduação em Linguística Aplicada na Universidade do Vale do Rio dos Sinos. Contato: anderson.carnin@gmail.com.
} 
Abstract: This paper presents an analysis of the professional development of a participant teacher from a continuing education course guided by the work with genre didactical projects (GUIMARÃES; KERSCH, 2012, 2014). Designing the notion of textual genre as a psychological instrument (MACHADO; LOUSADA, 2010) and focusing on the praxeological dimension of the teacher's writing, the article analyzes how the appropriation of this concept by the teacher allows the unveiling of the indicators of her professional development by the analysis of her writing. As a theoretical presupposition, it is assumed the perspective of socio-discursive interactionism (BRONCKART, 2006, 2013; FRIEDRICH, 2012), of didactical transposition (CHEVALLARD, 1985) and of didactic of writing (REUTER, 2013), aiming to analyze the modes of appropriation of the concept of genre didactical projects (in a didactic perspective) and its representation on the praxeological writing of the teacher. The results suggested that the professional development is deeply connected to the transformation of the concept of textual genre in a psychological instrument by the participant teacher.

Keywords: genre didactical projects; writing; professional development.

\section{Introdução}

O objetivo deste texto é discutir a formação do professor e o seu desenvolvimento profissional, articulando tais assuntos a partir da escrita que o professor produz ao planejar um projeto didático de gênero (PDG) (GUIMARÃES; KERSCH, 2012, 2014). A pesquisa que embasa este texto ${ }^{1}$ firmou-se a partir de um estudo de abordagem qualitativa, de viés interpretativo (CRESWELL, 2010), em que os saberes, o agir e o desenvolvimento profissional docente foram descritos sob uma ótica de práticas e sentidos que são atribuídos pelo professor ao/em seu trabalho e

${ }_{1}$ Trata-se de nossa pesquisa de doutoramento, intitulada "Na escrita do professor, um percurso possível para a análise do (seu) desenvolvimento profissional" (CARNIN, 2015), realizada junto ao Programa de Pós-Graduação em Linguística Aplicada da Unisinos, com apoio da Capes, através de bolsa Prosup de doutorado, sob orientação da Prof. ${ }^{a}$ Dr. ${ }^{a}$ Ana Maria de Mattos Guimarães. 
ao/em seu agir, na cultura em que está inserido. Nesse exercício, buscamos entrecruzar os saberes e representações do professor sobre seus saberes, sua formação e sua profissionalidade às questões relacionadas ao seu trabalho e à formação continuada da qual participou, cuja orientação seguiu parâmetros cooperativos $^{2}$ de realização. Para isso, focamos este texto em um aspecto específico: o conceito de gênero de texto na escrita do professor, notadamente na escrita praxiológica que ele produz ao planejar um projeto didático de gênero ${ }^{3}$. Ou seja: como o professor transforma um conceito científico em instrumento psicológico que influencia em seu trabalho - e como esse trabalho pode nos fornecer índices de seu desenvolvimento profissional - notadamente em uma perspectiva didática. Para situarmos melhor essa questão, retomamos, a seguir, alguns fundamentos teóricos que embasaram esta pesquisa.

\section{Gênero de Texto enquanto Instrumento Psicológico}

A partir de uma grande pesquisa acerca do funcionamento dos textos/ discursos, Jean-Paul Bronckart, principal epistemólogo do Interacionismo Sociodiscursivo (ISD), propôs um conceito de gênero de texto muito próximo do conceito bakhtiniano de gênero do discurso. Bronckart (1999, p. 101-102), à semelhança de Bakhtin (2003), define "gênero de texto como

${ }^{2}$ Em Guimarães e Carnin (2014), descrevemos mais detalhadamente os princípios dessa formação que se assenta sob a noção de cooperação.

3 "Um Projeto Didático de Gênero é uma proposta metodológica de didatização de gêneros. Traz como diferencial o fato de ser um projeto, voltado, portanto, para uma sequência de atividades que se realizarão dentro e fora da escola, de forma a garantir que o(s) gênero(s) tratado(s) esteja $(\mathrm{m})$ realmente ligados a uma prática social. Tal prática pode se dar no próprio âmbito da escola (o texto será publicado no jornal, no blog da escola, como pôster na parede, ou servirá para levar ao diretor/coordenador uma reivindicação dos alunos, etc.), como pode ir para além dos muros da escola. Neste caso, alia-se a práticas comunitárias (temáticas que dizem respeito ao local onde se localiza a escola: reivindicações do bairro, coleta seletiva de lixo, etc.) ou a práticas profissionais (como inscrever-se para um concurso/emprego; carta de recomendação, o que é isto; carta de apresentação para um emprego; curriculum vitae) e até a práticas políticas (debates, encaminhamento de reivindicações, conversa com autoridades)" (GUIMARÃES, 2014). 
tipos relativamente estáveis de enunciados, elaborados sócio-historicamente, por diferentes esferas das atividades humanas, sempre apresentando conteúdo, estruturação, relação entre os interlocutores e estilo específicos".

$\mathrm{Na}$ esteira do estudo realizado por Bronckart e seu grupo, o conceito de gênero de texto (ou gênero textual) - dada a adoção das reflexões metodológicas empreendidas por seu grupo - foi "adaptado" para o trabalho com gêneros no espaço escolar através das chamadas "sequências didáticas" (DOLZ; NOVERRAZ; SCHNEUWLY, 2004). Tal noção foi amplamente utilizada nas reflexões apresentadas pelos Parâmetros Curriculares Nacionais (BRASIL, 1998) aos professores da educação básica, conforme diferentes estudos permitem verificar (PEREIRA, 2010; BARROS; RIOS-REGISTRO, 2014, entre outros).

No cerne dessa proposta está também a releitura de Schneuwly e Dolz (2004) do conceito bakhtiniano de gênero do discurso. De base fortemente vigotskiana, a releitura dos autores do conceito de gênero do discurso propõe o conceito de gênero enquanto (mega)instrumento didático. $\mathrm{Na}$ proposição dos autores, no trabalho de ensino, o gênero assume tanto o papel de instrumento a comunicar quanto de objeto de ensino. Essa dupla articulação do gênero é que permite que ele funcione também como instrumento de desenvolvimento, tanto na dimensão do ensino quanto da formação continuada de professores. Expliquemos.

A compreensão de que, na teoria vigotskiana, "o objeto do instrumento psicológico não está no mundo exterior, mas na atividade psíquica do sujeito, sendo esse instrumento um meio de influência do sujeito sobre si mesmo, um meio de autorregulação e autocontrole" (FRIEDRICH, 2012, p. 57), permite-nos entender que o conceito de gênero de texto enquanto instrumento pode auxiliar o sujeito a realizar os fenômenos psíquicos necessários para desenvolver uma determinada tarefa (e, com isso, promover o desenvolvimento das capacidades necessárias para esse agir). Isso porque o conceito de gênero (e os próprios gêneros) de texto compreende(m) as três características elencadas por Vigotski para definir um instrumento psicológico:o: “1) é uma adaptação artificial; 2) tem uma natureza não orgânica, ou, em outras palavras, tem uma natureza social, e 3) é destinado ao controle dos próprios comportamentos psíquicos e dos outros" (FRIEDRICH, 2012, p. 58). 
Para melhor esclarecer esse pensamento, ecoamos as palavras de Machado e Lousada (2010, p. 625):

... o uso de um novo instrumento vai provocar transformações no ambiente físico ou social, nos outros que interagem com o sujeito, mas também sobre ele mesmo, fazendo com que ele tenha profundas transformações psíquicas, ou seja, aumente seus conhecimentos sobre o mundo físico e social, desenvolva capacidades para agir sobre o outro e sobre o mundo e regule seu comportamento.

Nessa perspectiva, a compreensão de que o professor, quando internaliza o conceito de gênero de texto, está contribuindo tanto para o seu desenvolvimento individual, pessoal, quanto para o da sua profissionalidade, reforça a hipótese de que o trabalho do professor não depende apenas de regulações externas (prescrições), mas também de modos de fazer que são próprios de cada trabalhador e do jeito com que eles se relacionam com o/ apropriam-se do conhecimento necessário para a realização de tarefas no curso de seu agir (autoprescrições/prefigurações). Essa hipótese fica também melhor elucidada quando consideramos, assim como Machado e Lousada (2010, p. 626), que o processo de internalização (ou de transformação de um artefato ${ }^{4}$ em um instrumento psicológico) é sempre situado, realizado de acordo com o momento sócio-histórico, com as intenções, capacidades e necessidades do sujeito. Quando se pensa sob a ótica do trabalho do professor, de sua profissionalidade e de seu desenvolvimento, poder-se-ia afirmar que:

${ }^{4} \mathrm{Na}$ concepção das autoras, artefatos “são 'objetos’ materiais ou simbólicos, sócio-historicamente construídos para mediarem a ação do homem sobre o meio ou sobre o outro e para se atingirem determinadas finalidades. Entretanto, nenhum artefato, em si mesmo, pode servir como esse elemento mediador da ação humana" (MACHADO; LOUSADA, 2010, p. 625). Assim, embora os artefatos possam estar à disposição do trabalhador, eles, por si só, não bastam para a realização da tarefa e o desenvolvimento do sujeito. É preciso que ocorra a apropriação, por si e para si, do artefato, para que possa ocorrer o desenvolvimento. Em Friedrich (2012), a discussão ocorre no âmbito da transformação de instrumento (encarado, nesse contexto, como sinônimo de artefato) em instrumento psicológico. É esta última concepção que adotamos neste texto. 
... não se trata de simplesmente utilizar o artefato como mandam as prescrições, mas de usá-lo de modo que ele seja útil para o próprio trabalhador e adaptado por ele mesmo às diferentes situações em que precisa utilizá-lo. Assim, é só quando algum artefato é apropriado pelo sujeito que ele passa a ser verdadeiro instrumento psicológico, na concepção da teoria vigotskiana. Trata-se, portanto, de uma construção psíquica, que permite o desenvolvimento de diferentes capacidades. Em relação aos gêneros, eles só poderão servir de mediadores para a comunicação e para o desenvolvimento linguageiro se forem apropriados pelo sujeito. (MACHADO; LOUSADA, 2010, p. 626).

Ao que nos parece, é intrínseca à atividade docente a necessidade de apropriação de inúmeros gêneros de texto (enquanto instrumentos psicológicos) e de práticas sociais de referência para que a transformação do trabalho (auto)prescrito/prefigurado em trabalho real seja bem-sucedida ${ }^{5}$. Sendo o trabalho do professor altamente orientado pela utilização de diferentes instrumentos, é na reelaboração desses instrumentos em suas práticas cotidianas de trabalho e formação que acreditamos poder ter acesso a índices que demonstrem a ocorrência (ou não) de seu desenvolvimento profissional. Nesse sentido, a mediação linguística que leva à transformação de diferentes artefatos em instrumentos psicológicos que propiciam o desenvolvimento do professor assume, para nós, papel nodal na compreensão do trabalho e desenvolvimento profissional do professor.

A compreensão de que um agir linguageiro se constrói pelo confrontamento das diferentes representações e compreensões engendradas pelos textos que os actantes produzem ao interatuarem em situações de (inter)ação social também funciona como justificativa e possibilidade de análise do desenvolvimento profissional docente. Apesar de não ser possível ter acesso direto à ação do ponto de vista psicológico, as interpretações da ação são possíveis a partir das e nas produções verbais realizadas pelos sujeitos. Assim, a interpretação das ações e do desenvolvimento dos professores

\footnotetext{
${ }^{5}$ Para esclarecimento sobre as diferentes dimensões do trabalho do professor, recomendamos a leitura de Bronckart (2006).
} 
parece ser possível a partir das representações presentes em seu agir linguageiro, sendo a escrita de trabalho uma dessas dimensões. No âmbito da escrita de trabalho, ainda selecionamos uma escrita em particular: o planejamento do PDG de uma professora que participou de um curso de formação continuada sobre a elaboração desse dispositivo didático no ano de 2011.

Cabe ressaltar que a classificação do projeto didático de gênero enquanto escrita praxiológica privilegia a relação que o conceito de gênero de texto assume nessa escrita. A dimensão do saber-fazer com o conceito em termos de prática(s) de trabalho, em detrimento de outras relações que poderiam ser evidenciadas a partir dessa escrita, é enfatizada nesta classificação. A relação do conceito de gênero de texto e desenvolvimento profissional é iluminada na análise dessa escrita a partir da noção de transposição didática ${ }^{6}$ (CHEVALLARD, 1985), da noção de gênero de texto e seu uso no campo da didática (REUTER, 2013) e da análise de índices de desenvolvimento marcados na escrita praxiológica do professor (elaborados a partir de Friedrich, 2012). A situação de interlocução dessa escrita, realizada para prefigurar um agir, também corrobora nossa classificação: produzida para guiar o trabalho do próprio professor, a escrita praxiológica tem função de conduzir uma ação (práxis) didática (docente).

Acreditamos que a análise desses escritos do professor, entendidos como "processos" de um continuum de desenvolvimento, pode servir para apreendermos a emergência de índices de reconfiguração de um conceito científico em instrumento psicológico. Ao descrevermos os elementos linguísticos presentes na reconfiguração psíquica desse conceito, esperamos trazer contribuições para o campo do desenvolvimento profissional de professores (em formação continuada), tópico de nossa próxima seção.

${ }^{6}$ O conceito de transposição didática baseia-se nas transformações que pelas quais passam os saberes desde que eles entram no sistema didático. Desenvolvido por Chevallard (1985), refere-se ao processo fundamental que possibilita que se transforme em objeto de ensino um conteúdo de caráter científico. Ou seja, o processo de transposição didática permite que se construa uma versão didática do saber a ser aprendido, no caso, do gênero de selecionado para a produção de um PDG. 


\section{Breves Apontamentos sobre a Noção de Desenvolvimento (Profissional)}

A noção de desenvolvimento humano abarca múltiplas compreensões, de acordo com a área do conhecimento ou vertente teórica a que recorremos para defini-lo. A fim de melhor delimitar o escopo de nossa investigação, focalizaremos exclusivamente a perspectiva do desenvolvimento humano apresentada no quadro do interacionismo social de base vigotskiana (FRIEDRICH, 2012; BRONCKART, 2013, entre outros), assumindo o risco da omissão de outras correntes ou perspectivas teóricas também relevantes.

Neste artigo, importa-nos focalizar a relação entre linguagem e desenvolvimento profissional. Isso porque é a partir das significações da linguagem, contextualizadas e de ordem sociocultural, das quais o sujeito se apropria, que o seu desenvolvimento pode ser potencializado. A formação continuada de professores e a apropriação de conceitos científicos e sua posterior transformação em instrumento psicológico nesse cenário podem ser relacionados a esse movimento que auxilia o sujeito a forjar novas significações sobre o mundo e sobre as ações que nele realiza. Mas como podemos explicitar essa relação (entre linguagem e desenvolvimento)?

É verdade que a relação entre conhecimento e desenvolvimento está intimamente ligada à questão do psiquismo, ou de consciência, como alguns momentos da obra de Vigotski permitem perceber, de acordo com Friedrich (2012, p. 47). Nessa perspectiva, o psiquismo humano funciona como um "filtro" que seleciona certos elementos estáveis da realidade e os transforma de modo que seja possível agir a partir disso. O psiquismo, assim, não representa fielmente o mundo, mas, antes disso, "trabalha o mundo" (FRIEDRICH, 2012, p. 49). Nesse sentido, ele distorce subjetivamente a realidade em favor do organismo. Mas como a formação continuada e um conceito científico podem intervir na ação do psiquismo? Como essas ações podem impulsionar o desenvolvimento profissional de professores?

É preciso lembrar que isso não se dá de um modo direto. É somente de um modo mediatizado, por meio de conceitos, de reconstruções, que a produção de conhecimento é possível e passível de motivar desenvolvimento. Da mesma forma, Vigotski (2009) descreve a relação entre a atividade de 
trabalho e a questão do emprego de ferramentas (que podem ser entendidas, aqui, como instrumentos) do seguinte modo:

... não podemos explicar satisfatoriamente o trabalho como atividade humana voltada para um fim, afirmando que ele é desencadeado por objetivos, por tarefas que se encontram diante do homem; devemos explicá-lo com o auxílio do emprego de ferramentas, da aplicação de meios originais sem os quais o trabalho não poderia surgir; de igual maneira, para a explicação de todas as formas superiores de comportamento humano, a questão central é a dos meios através dos quais o homem domina o processo do próprio comportamento. (VIGOTSKI, 2009, p. 161).

A teoria vigotskiana permite que a noção de instrumento psicológico seja considerada como ferramenta, pois transforma o vínculo entre o instrumento (o conceito de gênero de texto, em nosso caso) e o processo psíquico necessário para resolver a tarefa (tomada de consciência sobre o conceito, a fim de falar/escrever sobre ele/a partir dele, tanto em uma dimensão praxiológica quanto epistêmica). E é na observação do emprego do instrumento psicológico, espontaneamente mobilizado pelo sujeito na e para a realização de determinada tarefa, que podemos observar traços de sua transformação. A grande diferença entre instrumento e instrumento psicológico, nesse caso, está no fato de que "o objeto do instrumento psicológico não está no mundo exterior, mas na atividade psíquica do sujeito, sendo esse instrumento um meio de influência do sujeito sobre si mesmo, um meio de autorregulação e autocontrole" (FRIEDRICH, 2012, p. 57), como já discutido anteriormente.

O que precisa ser lembrado aqui é que a função dos instrumentos psicológicos é estritamente artificial e age sobre os processos psíquicos, que são naturais. E é o controle artificial dos processos psíquicos, com o auxílio de instrumentos psicológicos, que se caracteriza como a essência do processo de desenvolvimento para Vigotski, segundo Friedrich (2012, p. 63). Ainda segundo a referida autora: 
Utilizando os instrumentos psicológicos, o homem controla e influencia seu comportamento psíquico, sem que se misture nesse processo, já que ele não faz nada mais que intercalar entre ele e seus processos psíquicos determinados meios que agem diretamente sobre seu próprio comportamento psíquico, a fim de produzir o objeto desejado. O sujeito se transforma, pela utilização do instrumento, em objeto visado por esse último. Com a ajuda dos instrumentos psicológicos, o sujeito faz com que se produza em si mesmo determinados efeitos desejados, do qual é objeto. Poder-se-ia dizer também que o sujeito é, ao mesmo tempo, ativo e passivo, o que justamente constitui a especificidade da atividade mediatizante no plano psicológico. (FRIEDRICH, 2012, p. 66-67).

Talvez o momento exato dessa transformação do conceito em instrumento psicológico não possa ser apreendido na ocasião de sua ocorrência. No caso que nos interessa, o do desenvolvimento de professores, sua apreensão foi pensada a partir da escrita do professor, que pode denotar índices de influência, autorregulação ou autocontrole (categorias assumidas para a análise do desenvolvimento neste texto) por parte da docente em formação continuada e desenvolvimento profissional cuja escrita praxiológica é aqui analisada.

Tal transformação, evidentemente, não é linear. É, antes disso, marcada por continuidades e rupturas. O que buscamos não é evidenciar o surgimento do conceito, e, para que a transformação do conceito em instrumento psicológico funcione como vetor de desenvolvimento, é necessário que o professor que entra em contato com o conceito o tome como elemento externo de seu agir. O conceito de gênero de texto, então, enquanto elemento externo, pode suscitar, no professor que reflete sobre ele, uma contradição ou conflito com a organização psíquica herdada (BRONCKART, 2013, p. 90). Essa contradição, ou conflito, em termos de aprendizagem, tem a ver com a "zona de desenvolvimento proximal" conceitualizada por Vigotski (2009). A relação entre aquilo que o sujeito sabe e o que ainda pode aprender, sob a supervisão ou com a ajuda de um par mais experiente, pode contribuir para seu desenvolvimento. Isso, no entanto, só ocorre 
... na medida em que os conflitos que eles [os aportes externos na ZDP] geram sejam 'gerenciáveis' pela pessoa em seu estado atual de desenvolvimento; e nesse sentido, a definição desta 'zona' de eficácia é sempre uma 'aposta', o formador propõe os elementos que lhe parecem ser exploráveis à pessoa em questão, mas é esta última, e ela somente, que se desenvolve... ou não. (BRONCKART, 2013, p. 90).

Assim, parece pertinente investigar os efeitos desenvolvimentais da escrita praxiológica do professor em uma formação continuada que investiu na cooperação como princípio e no conceito de gênero de texto como um de seus pilares essenciais. Esse desenvolvimento pode ser descrito com a finalidade de ajudar a melhor compreendermos os processos envolvidos no desenvolvimento de conceitos científicos, de capacidades de ação a partir de tais conceitos e das próprias pessoas envolvidas. A reflexão que a produção escrita demanda dos professores, além de poder suscitar o seu desenvolvimento, pode também tornar visível alguns elementos relacionados à tomada de consciência que a formação continuada possibilita.

Assim, o desenvolvimento profissional pode ser entendido, a partir de Bronckart (2013), como uma reconfiguração de representações individuais sobre determinado aspecto do trabalho do professor. Essa reconfiguração é pautada na tomada de consciência, que é perpassada pela reflexão, pelo debate interpretativo (da ação) e pela atribuição de uma nova significação à representação em voga, total ou parcialmente. Isso ocorre em um meio social cuja dinâmica interacional propicia uma "aprendizagem epistêmica" (BOTA, 2011), cujos traços são apreensíveis, de maneira indireta, no agir de linguagem dos sujeitos em (contínuo) desenvolvimento profissional.

Interessa-nos, pois, observar quais categorias de desenvolvimento profissional passam pela escrita de trabalho do professor. Nossa hipótese é que essas categorias estão intimamente ligadas à textualização de diferentes gêneros de texto, nos quais os tipos de discurso assumem papel nodal da configuração de modos de raciocínio que podem denotar efeitos desenvolvimentais e uma reestruturação psíquica (positiva), com a qual o sujeito opera em suas representações. Desse modo, buscamos, com esta pesquisa, contribuir para a área de estudos ao desvelar mais especificamente 
como o conceito de gênero de texto é internalizado pelo professor em formação continuada e é reconfigurado em seu agir, exclusivamente em sua dimensão praxiológica. Para isso, valemo-nos do seu planejamento de um projeto didático de gênero (PDG) (GUIMARÃES; KERSCH, 2012, 2014) produzido pela professora Alice ${ }^{7}$, a partir do qual focalizamos a emergência e tratamento de segmentos temáticos ${ }^{8}$ que remetam ao trabalho didático com o conceito de gênero de texto.

\section{Alice e o (seu) Desenvolvimento Profissional}

Entre as múltiplas demandas de um professor está a necessidade de orientar-se para a realidade sociocultural do seu lugar de atuação. Muitas vezes, é o contexto da sala de aula - ou da escola - que (re)orienta o(s) fazer(es) do professor. Com a professora Alice não foi diferente. Em 2011, enquanto participava da "comunidade de indagação", outra "indagação" surgia em suas reflexões: por que em sua escola, muitas vezes, há um silenciamento em relação às múltiplas e diversas etnias que compõem o cenário da sala de aula e a realidade local? Por que se mantém o status quo em relação à crença de que a realidade local é composta apenas da cultura branca, em grande parte formada por descendentes de imigrantes europeus? Somou-se a essas indagações o fato de que, na turma em que o PDG objeto desta

\footnotetext{
${ }^{7}$ Nome fictício atribuído à colaboradora da pesquisa. Alice é professora de Língua Portuguesa, concursada da rede municipal de ensino de Novo Hamburgo (RS) e participou da formação continuada sobre elaboração de PDGs entre os anos de 2011 e 2012.

${ }^{8}$ Segmentos temáticos, no âmbito desta pesquisa, são os "momentos" do texto em que Alice tematiza, em sua escrita, o conceito de gênero de texto. Em geral, essa tematização articula-se justamente em torno de elementos lexicais que remetam ao conceito em voga, tendo como critério de segmentação unidades sintáticas como orações ou períodos compostos.

9 "Comunidade de indagação" é o nome dado ao coletivo de professores, pesquisadores e acadêmicos de Letras e Linguística Aplicada que se reuniram, semanalmente, para discutir questões de ensino de língua materna e formação de professores no âmbito do projeto que subsidia essa investigação. Uma explicação mais detalhada desse conceito pode ser encontrada em Guimarães e Kersch (2012).
} 
análise foi aplicado, havia um aluno negro que se "encolhia" toda vez que se falava sobre a cor de sua pele ou sobre cultura afro-brasileira em sala de aula. Alice percebeu isso e decidiu trazer elementos dessa cultura afro-brasileira para a aula de Língua Portuguesa. Optou por trabalhar com um gênero da oralidade que tem relação direta com elementos da cultura africana e da literatura que expressa um pouco dessa identidade: a ladainha de capoeira.

Seu PDG teve, então, origem e finalidade claramente definidas: surgiu a partir da necessidade de trabalhar, em sala de aula, a questão da identidade racial/cultural. Em uma turma de $6^{\circ}$ ano, pertencente a uma realidade sociocultural majoritariamente branca, descendentes de alemães, como ocorre com frequência na região do estado em que Alice trabalha, ocorria um silenciamento da identidade afro-brasileira, que também era parte do conjunto de etnias que compunham a classe, como já mencionado. A professora Alice, ao perceber esse silenciamento, optou pelo trabalho com um gênero que levasse a sua turma a pensar um pouco mais sobre a forma como a cultura negra está (ou pode estar) presente na realidade da comunidade escolar e da sociedade, especialmente em termos de cultura oral.

A escolha pela ladainha de capoeira, segundo a professora Alice, deveuse à preocupação em valorizar a cultura africana presente em nossa sociedade, notadamente a produção literária reproduzida a partir de cantigas, jogos e ladainhas, acessíveis aos alunos pela sua presença no dia a dia, mas muitas vezes despercebida ou não valorizada. Esse trabalho com o gênero ladainha de capoeira foi considerado, pela professora, essencial para resgatar a questão da identidade afro-brasileira com os alunos. Isso porque o estudo desse gênero permitiu aos alunos compreender um pouco mais sobre a história da mestiçagem afro-brasileira, bem como valorizar a própria história de muitos alunos através do estudo desse gênero de texto e suas relações culturais, históricas e sociais.

A partir dessa escolha é que se deu o trabalho descrito a seguir em maior profundidade, respeitando a organização e a denominação das oficinas do PDG em "aulas", conforme a própria Alice o fez. 


\section{Uma Análise da Escrita (das Aulas) do PDG "Ladainha de Capoeira"10}

O PDG sobre ladainha de capoeira foi planejado para ser realizado com uma turma de $6^{\circ}$ ano do Ensino Fundamental de uma escola pública da periferia da cidade de Novo Hamburgo/RS, em 2011. A professora Alice cedeu-nos seu planejamento ${ }^{11}$, que serviu de material para nossa análise. É interessante mencionar, em termos metodológicos, que, no primeiro semestre de 2011, quando da produção do PDG aqui apresentado, atuávamos em um duplo papel na "comunidade de indagação" da qual Alice era membra: fazíamos parte da equipe de formadores dos professores da rede municipal de Novo Hamburgo, bem como realizávamos nossa pesquisa de tese vinculados ao projeto de pesquisa "Por uma formação continuada cooperativa para o desenvolvimento do processo educativo de leitura e produção textual escrita no Ensino Fundamental" (Capes/Inep, edital 038/ 2010) que sustentava essa formação. Assim, tivemos envolvimento direto com Alice quando de sua participação na formação continuada, acompanhando o processo de produção de seus projetos didáticos de gênero, bem como acompanhamos o processo de filmagem das aulas relacionadas a esses projetos didáticos, auxiliamos no processo de gravação das reuniões em que se discutiam essas aulas e, por fim, colaboramos na realização de entrevistas semiestruturadas com os participantes dessa pesquisa. Esse trabalho de geração de dados contou com a ajuda de mais duas doutorandas, três

${ }^{10}$ Compete salientar que este foi um dos primeiros PDGs elaborados sob o signo deste conceito que, à época, ainda estava em elaboração. Assim, muitas "inconsistências" poderiam ser apontadas neste planejamento, quando comparado ao que Guimarães e Kersch $(2012$, 2014) propõem sobre o trabalho com PDGs. Preferimos, no entanto, entender essas "inconsistências" como parte do processo de apropriação e desenvolvimento da professora Alice e tratamos o material por ela produzido como um PDG porque, para estas análises, não é a fidelidade aos princípios metodológicos que nos interessa a priori, mas, antes, a relação e referência a um dos princípios teóricos basilares: o conceito de gênero de texto. Como demonstraremos em tempo, isso ocorre no planejamento de Alice.

${ }^{11}$ A realização desta pesquisa teve autorização do Comitê de Ética em Pesquisa da Unisinos (Projeto CEP 12/054), tendo Alice assinado um termo de consentimento livre e esclarecido para sua participação em nossa investigação. 
mestrandas e seis bolsistas de Iniciação Científica vinculados ao projeto supracitado, além da supervisão das duas pesquisadoras que o coordenavam.

A geração dos dados desta pesquisa, então, deu-se de forma longitudinal, compreendendo um total de oito semestres, entre 2011 e 2014, período da realização do projeto supracitado. Especificamente com relação aos dados de Alice, o recorte se deu entre o primeiro semestre de 2011 e o segundo semestre de 2012, período de tempo no qual Alice fez parte da "comunidade de indagação" e da formação continuada. Uma cópia do PDG aqui analisado foi coletada, em fotocópia do manuscrito original, no segundo semestre de 2011, após sua aplicação em sala de aula. O depoimento de Alice foi produzido em entrevista semiestruturada, realizada no segundo semestre de 2012, quando de seu desligamento da "comunidade de indagação" por motivos de ordem pessoal.

Ressalte-se que, ao invés de apresentarmos seu PDG na íntegra para depois analisá-lo, neste texto, dadas as limitações de espaço, optamos por já apresentarmos a análise que dele realizamos, a fim de tornar mais clara nossa posição sobre a transformação do conceito de gênero de texto em instrumento psicológico como um movimento de desenvolvimento profissional. Tomando, então, a leitura descritivo-analítica por nós empreendida da escrita praxiológica de Alice em seu PDG como referência, passamos a analisar, aula a aula, o trabalho proposto com o conceito de gênero de texto ${ }^{12}$.

\section{Aula 1}

Essa aula foi dedicada à apresentação do gênero oral ladainha de capoeira. A professora fez esse trabalho a partir de pesquisa, em dicionários e na internet, do vocábulo "ladainha". Realizada a pesquisa, os alunos construíram, coletivamente, o conceito de "ladainha". Esse conceito baseado em pesquisas bibliográficas foi contrastado com o que os alunos sabiam empiricamente sobre o gênero, a partir de suas vivências pessoais. Hipóteses foram levantadas e anotadas para, posteriormente, serem comparadas com

\footnotetext{
${ }^{12}$ Dadas as limitações deste artigo, ao leitor interessado informamos que uma descrição mais densa das categorias de análise empreendidas nessa análise da escrita praxiológica de Alice pode ser encontrada em nossa tese de doutoramento (CARNIN, 2015).
} 
os conhecimentos que seriam construídos ao longo do PDG. A discussão realizada em sala de aula levou alunos e professora a confrontarem o sentido pejorativo que, muitas vezes, palavras de origem africana têm em nossa sociedade. A partir desse confrontamento, Alice apresentou o áudio de uma ladainha de capoeira. Feita a audição, os alunos tiveram acesso à letra da ladainha em cópia impressa, para realizarem atividades de leitura silenciosa e oral do texto. Alice iniciou, então, o trabalho de estudo sobre a estrutura do gênero, destacando elementos da situação de interlocução, da composição, do ritmo e do tema da ladainha selecionada. Como tarefa extraclasse, Alice solicitou aos alunos que escrevessem um "parágrafo" sobre questões abordadas em aula, como escravidão, capoeira, instrumentos utilizados na capoeira, negros, religiosidade e crenças. Podemos entender essa atividade como a produção de um outro gênero dentro do PDG, o que amplia o escopo do trabalho previsto, com um ou dois gêneros, já no início do trabalho. Essa produção escrita deveria levar em conta a análise da ladainha "Antigamente", realizada em aula, bem como o conteúdo que foi trabalhado nas aulas de História e Arte, disciplinas que se engajaram no trabalho interdisciplinar proposto por Alice em seu PDG.

\section{Aula 2}

Essa aula teve início com a leitura dos "parágrafos" escritos pelos alunos como tarefa extraclasse. A professora tomou nota, na lousa, das informações mais relevantes trazidas pelos alunos. A partir disso, a temática estava novamente posta e ela pode engajar os alunos na leitura de outras duas ladainhas de capoeira, explicar o ritual que existe nesse jogo, como a primeira ladainha ser a que convida os jogadores a participarem da roda e as seguintes abordam temas mais simples e usam frequentemente da repetição do refrão para facilitar a concentração no jogo; o fato de que o mestre, ou quem ele indicar, é quem vai cantar as músicas da roda; o respeito à hierarquia do mais velho ou mais experiente da roda. A seguir, eles ouviram as músicas das ladainhas, com Alice explicando o que são ladainhas de capoeira Angola - dando uma especial ênfase às características do gênero - e puderam ler as letras das músicas também.

As atividades de leitura propostas por Alice para as ladainhas de capoeira dessa aula exploraram o que os textos tinham em comum, o que 
tinham de diferente, questionaram os alunos sobre a existência de outros textos semelhantes a esses, se os alunos respondessem que sim, em que aspectos e onde eles ouviram ou leram tais textos semelhantes às ladainhas. As atividades dessa aula incluíram ainda a apresentação de alguns instrumentos utilizados no jogo da capoeira, a possibilidade de os alunos interagirem com os instrumentos, bem como cantarem e aprenderem o ritmo das ladainhas apresentadas. Por fim, a professora e os alunos realizaram a leitura de um texto informativo (verbete) relativo a ladainha de capoeira, sobre o qual os alunos responderam a um questionário de compreensão de leitura.

\section{Aula 3}

A partir da releitura da ladainha da aula anterior, Alice e seus alunos retomaram os assuntos desenvolvidos nas aulas de Língua Portuguesa, História e Arte sobre a capoeira no tempo da escravidão e a própria história da escravidão no Brasil. Tópicos importantes sobre esses assuntos foram anotados para servirem de base à produção das ladainhas de capoeira dos alunos. Alice explicou as peculiaridades da linguagem oral na ladainha, na qual a sonoridade rítmica produz cadência, o que facilita a memorização, e também discutiu aspectos relacionados à variação linguística presentes nesse gênero de texto. Ressaltou que, em termos de temática, a ladainha pode tratar de questões culturais afro-brasileiras, falar da história do negro, no Brasil ou na África, ou apenas brincar com as palavras.

Questões sistemáticas sobre a linguagem (registro formal ou coloquial) do gênero, a estrutura, a função social do gênero e ainda de léxico também foram realizadas nessa aula, aprofundando o conhecimento dos alunos sobre ladainhas de capoeira.

\section{Aula 4}

A leitura do texto "A capoeira", do livro África e o Brasil africano (SOUZA, 2007) foi o mote dessa aula. A partir dessa leitura, questões sobre léxico e, principalmente, sobre o tema, foram realizadas. A professora solicitou, durante a interpretação do texto, que os alunos identificassem e se posicionassem sobre o "dilema" que o texto menciona: enfatizar as raízes da África (continente) ou focar na valorização da cultura produzida no Brasil a 
partir da mestiçagem: a cultura afro-brasileira. Essa atividade gerou novos apontamentos, anotados para serem empregados na produção da ladainha de capoeira dos alunos.

\section{Aula 5}

Novas ladainhas de capoeira foram apresentadas aos alunos durante essa aula, com Alice chamando a atenção deles para a estrutura do gênero e a função que distintas ladainhas, com estruturas diferenciadas, assumem na roda de capoeira. A ladainha de maior complexidade é utilizada para iniciar o jogo, chamando os capoeiristas à roda enquanto a luta ainda não é realizada. As demais ladainhas cantadas na roda são de menor complexidade e se valem da repetição do coro para que a sequência e o ritmo de fácil memorização permitam aos jogadores se concentrar no jogo enquanto cantam.

Alice trabalhou a identificação do tema das ladainhas apresentadas, as rimas, o significado de palavras desconhecidas e, claro, a história que estava sendo contada pela ladainha. O ritmo do gênero foi trabalhado com exploração do próprio corpo, das mesas e de um pandeiro, além de ser cantada pelos alunos. Essa atividade foi acrescida de uma identificação das palavras-chave das ladainhas estudadas, permitindo aos alunos realizarem uma conversa com os professores de História e Arte sobre as questões que elas suscitam, além de buscas na internet sobre os assuntos que tais palavras envolvem.

Os alunos foram orientados a refletir sobre o conteúdo das ladainhas, mas também sobre que outros tipos de textos (ou melodias, ou músicas) têm características semelhantes à ladainha de capoeira. A expectativa de Alice era que os alunos notassem que são as cantigas de roda que possuem semelhanças em relação à linguagem e ao ritmo das ladainhas de capoeira.

Outros aspectos explorados por Alice nessa aula foram a formação de quadrinhas (estrofes de quatro versos), a rima, a repetição de expressões e a temática das ladainhas. Essa atividade deu origem à tarefa extraclasse solicitada por Alice nessa aula: a elaboração de uma quadrinha pelos alunos, para ser entregue na próxima aula. Os alunos que quisessem, poderiam apresentar sua quadrinha à turma. Salientamos que essa atividade também pode ser considerada como a produção de um outro gênero no PDG 
desenvolvido, ultrapassando, como se percebe, a indicação do procedimento didático de trabalhar com um ou dois gêneros de maneira sistemática e aprofundada.

\section{Aula 6}

Essa aula foi dedicada à temática das ladainhas e à cultura afro-brasileira e contou com a participação de diferentes atores nessa atividade. Alice convidou uma funcionária da escola para falar aos alunos sobre a religião Umbanda, orixás, benzedura, enfim, sobre elementos tradicionalmente relacionados à cultura afro. Ainda nessa aula, Alice convidou alunos de outra turma de $6^{\circ}$ ano para apresentar uma pesquisa sobre "os negros" e a cultura afro-brasileira a essa turma, trazendo à aula conhecimentos diferentes daqueles que foram apresentados junto das ladainhas de capoeira. Outro aspecto fortemente trabalhado por Alice com seus alunos nessa aula foi a questão das palavras africanas utilizadas em nosso dia a dia, bem como seus significados e o valor que assumem em determinados contextos. Esse trabalho demonstra uma preocupação saliente de Alice no trabalho com o léxico, que, inclusive, foi reforçado em outras aulas.

\section{Aula 7}

A sétima aula teve um trabalho particular com atividades de leitura: a narrativa Amanhecer Esmeralda, de Ferréz (2005), foi lida pela professora em conjunto com os alunos, na biblioteca da escola. Questões específicas que relacionam a leitura da obra à leitura do mundo dos estudantes foram realizadas por Alice, que discutiu com seus alunos a relação entre a história narrada e a realidade deles. As ladainhas de capoeira já trabalhadas foram retomadas nessa aula, de modo a reforçar a marcação do ritmo e dos toques.

\section{Aula 8}

O filme que narra a lenda do capoeirista "Besouro" foi trazido por um aluno para ser assistido nessa aula. Alice, além de assistir ao filme com os alunos, propôs comentários sobre a película, discutindo diferenças entre as vertentes "regional" e "Angola" da capoeira, os golpes marciais que aparecem no filme, os orixás, a lenda do Besouro, o fantástico e o real. 


\section{Aula 9}

Nessa aula os alunos puderam experienciar a vivência de uma roda de capoeira, cantando e tocando as ladainhas de capoeira trabalhadas em aula com um mestre de capoeira convidado por Alice. Ele contou aos alunos a história da capoeira, discorreu sobre palavras de origem africana, ensinou mais algumas ladainhas e falou sobre certos movimentos da capoeira.

\section{Aula 10}

A partir de tudo o que foi trabalhado sobre o tema da cultura afrobrasileira e o gênero em estudo, os alunos de Alice, nessa aula, produziram uma letra de ladainha de capoeira.

\section{Aula 11}

Nessa aula os alunos produziram um CD com a coletânea de letras de ladainha escritas por eles. As letras foram musicadas e gravadas em áudio. Para o CD foi produzido um encarte com as letras e alguns trabalhos realizados na aula de Arte serviram como ilustração para a capa. Os alunos realizaram uma avaliação do projeto, uma autoavaliação sobre o seu aprendizado e uma avaliação específica da ladainha de capoeira produzida por eles. Para isso, valeram-se de uma grade de avaliação sobre o gênero, a seguir transcrita:

Avaliação da ladainha de capoeira: marque um x na opção que responde à pergunta sobre seu trabalho

\begin{tabular}{|l|l|l|l|}
\hline & Sim & Não & Pouco \\
\hline O conteúdo da sua ladainha é criativo? & & & \\
\hline A ladainha que você escreveu ensina algo às pessoas? & & & \\
\hline $\begin{array}{l}\text { O seu texto está escrito em forma de ladainha (com } \\
\text { versos, rimas, pequenas frases, refrão)? }\end{array}$ & & & \\
\hline Tem erros de ortografia? & & & \\
\hline Tem título? & & & \\
\hline
\end{tabular}

Fonte: Alice (2012). 
A grade de avaliação proposta pela professora, em conjunto com seus alunos, sistematiza aspectos trabalhados em suas aulas a respeito do gênero ladainha de capoeira, evidenciando aspectos a partir dos quais os alunos serão avaliados e nos permitindo acessar elementos de sua escrita praxiológica acerca do trabalho didático com o conceito de gênero de texto. Apesar de contribuir para a (meta)reflexão dos alunos sobre a produção textual por eles realizada, além de sinalizar para quais aspectos do gênero a professora considera essenciais em sua produção, a grade poderia, para fins didáticos, ser complexificada, solicitando aos alunos que, em sua autoavaliação dos textos, justificassem o sim ou não dado a cada item da grade, de modo a favorecer o desenvolvimento de suas capacidades de revisão, reescrita e mesmo de análise linguística de suas produções escritas.

Como anunciado, a descrição das aulas apresentadas traz uma perspectiva de análise sobre as oficinas e o trabalho que Alice realizou em sala de aula com o PDG sobre ladainhas de capoeira. Reforçamos que a opção de não reproduzir o manuscrito que contém a escrita de seu PDG respeita as questões de autoria do material (ainda não publicado pela autora) e, também, por entendermos que, ao apresentarmos a análise do material escrito de Alice, priorizamos as reflexões sobre seu (possível) desenvolvimento profissional a partir da análise de sua escrita praxiológica, a qual tem intrínseca relação com as atividades realizadas em sala de aula. Essa opção, no entanto, não é livre de restrições, as quais podem ser mais bem dimensionadas em investigações futuras.

Sobre seu trabalho didático com o conceito de gênero de texto, podemos perceber que o trabalho prefigurado de Alice traz à discussão elementos relacionados às designações do gênero por ela selecionado, notadamente na Aula 2, em que ela se detém a explicar o que é o gênero "ladainha de capoeira Angola". Embora seu planejamento não traga em detalhes como essa atividade foi realizada, é possível depreender que Alice tomou as semelhanças - e diferenças - desse gênero com outro(s), como a(s) cantiga(s) de roda, como parâmetro para a realização da atividade. Assim, seus alunos puderam comparar a estrutura de um gênero pouco conhecido em sua realidade a outro com o qual, talvez, estivessem mais familiarizados, notando especialmente as semelhanças entre eles. Esse foi um ponto de partida interessante para engajar os alunos no trabalho com um texto até então desconhecido por eles. 
Sobre a designação do gênero (REUTER, 2013), é relevante destacar que ela está intimamente ligada à prática da capoeira em suas diferentes vertentes, como a Aula 8 nos permitiu visualizar. As vertentes "Angola" e "regional" da capoeira e da ladainha foram abordadas por Alice, demonstrando aos alunos a relação entre o gênero e a prática social a que ele se vincula. Pode-se perceber uma preocupação da professora, ainda que não sistemática nesse momento de seu trabalho, de trabalhar as designações do gênero, especialmente da "ladainha de capoeira Angola", com a qual ela trabalha em seu PDG, mostrando aos alunos que um pouco da especificidade do gênero passa pela prática social/cultural que o engendra.

Essa questão também está intimamente ligada aos conteúdos específicos veiculados pelo gênero. É a especificidade da ladainha de capoeira Angola que demanda dos alunos a aprendizagem acerca do que pode ser dito nesse/com esse gênero. A Aula 3 nos mostra essa preocupação de Alice, quando ela lembra a seus alunos que, além de tratar de questões culturais afro-brasileiras, fazer menção aos instrumentos utilizados na capoeira ou falar da história do negro no Brasil ou na África, a ladainha de capoeira Angola pode somente propor uma brincadeira com as palavras.

Questões de estrutura composicional do gênero também foram amplamente trabalhadas por Alice, especialmente a rima, a repetição de expressões, a formação de quadrinhas (como a Aula 5 nos permite vislumbrar). O ritmo (sonoro) que esse gênero demanda também foi um aspecto muito trabalhado por Alice em sua abordagem didática da ladainha de capoeira (as Aulas 5 e 7 ilustram bem isso). Essa abordagem do ritmo remete ainda à questão do suporte do gênero, neste caso vinculado à oralidade. Nas Aulas 5 e 7, Alice trabalhou claramente com esse aspecto do gênero, além de retomar isso quando, na Aula 11, gravou com os alunos um CD com as ladainhas de capoeira que eles produziram.

Quanto ao estudo das marcas gráficas (REUTER, 2013), que se relacionam mais com a escrita que a oralidade, Alice não apresentou atividades que oportunizassem um estudo sistemático sobre esse aspecto, talvez pelo fato de ele não ser pertinente ao gênero trabalhado. A ladainha de capoeira é um gênero eminentemente oral, sendo a escrita apenas uma forma de transcrição e registro do gênero, e não um meio pelo qual ele costumeiramente é produzido nas práticas sociais de referência. 
As características enunciativas do texto, no entanto, são bastante pertinentes ao trabalho com esse gênero. Alice faz sua transposição didática em atividades que provocaram reflexões nos alunos, especialmente sobre o registro de linguagem utilizado no gênero, que traz marcas de coloquialidade e faz parte de uma das variedades da língua portuguesa brasileira (a Aula 2 demonstra isso, especialmente quando Alice trabalha com a distinção norma coloquial x norma culta). Outro aspecto fortemente trabalhado por ela em seu PDG tem relação com as unidades lexicais que são apropriadas ao gênero ou que nele são comumente empregadas. Diferentes momentos do PDG (Aulas 3, 6 e 9) trataram da questão do léxico, seja no prisma da significação, seja no prisma da etimologia dos vocábulos que costumam aparecer no gênero ladainha de capoeira.

A questão dos sistemas semióticos pertencentes ao gênero está alinhada à exploração realizada por Alice das marcas da oralidade, como ritmo, rima e, também, dos instrumentos musicais que acompanham a ladainha de capoeira, ajudando na composição e significação do gênero em relação à prática social da roda de capoeira.

As formas sintáticas presentes no gênero foram exploradas na Aula 5, quando a formação de quadrinhas (estrofes com 4 versos) é trabalhada por Alice. De alguma maneira, esse trabalho certamente alertará os alunos para elementos relacionados à sintaxe do texto da ladainha, que possivelmente organizará os elementos dos enunciados em versos de modo diverso do que seria feito em prosa. Os tipos de discurso, no sentido bronckartiano do termo, ou mesmo as sequências textuais, não foram alvo de preocupação explícita de Alice na exploração do gênero textual nesse PDG. Esse, talvez, seja um aspecto que poderia ter sido mais bem desenvolvido em seu trabalho, especialmente quando se considera que, em determinados momentos de seu planejamento, Alice trouxe para as aulas gêneros diferentes da ladainha (e.g. "parágrafo sobre as questões levantadas em aula" na Aula 1; verbete, na Aula 2; cantigas de roda, na Aula 3; entre outros), que possibilitariam um estudo contrastivo da estrutura textual desses gêneros em relação à ladainha, por exemplo.

Talvez por ter se detido com maior afinco em questões de interlocução, de conteúdo temático ou de infraestrutura, em termos de extrato sonoro especialmente, Alice direcionou sua exploração de elementos linguísticos que 
compõem o gênero principalmente para aquilo que auxilia a ladainha a ser lembrada "de memória" e cantada, mostrando aos alunos uma face do gênero mais ligada à função social (denunciar a situação do negro na sociedade através da música que faz parte de um jogo oriundo da tradição afrobrasileira) e à forma como o texto se organiza para dar conta dessa prática. Se outros elementos linguístico-textuais não foram explorados em profundidade por Alice em seu trabalho com esse gênero - ou com os outros gêneros que ela convoca para auxiliar no desenvolvimento de seu projeto -, isso, no entanto, não desqualifica o trabalho de transposição didática da professora, que levou para a sala de aula um gênero de texto ainda não explorado em seu cenário de atuação (e, salvo uma pesquisa mais aprofundada ou casos que desconheçamos, no cenário brasileiro como um todo) e construiu um projeto que explora em profundidade a temática que lhe dá origem: a questão da cultura e da identidade afro-brasileira.

\section{Considerações (nem tão) Finais}

Retomando nossa asserção principal, acerca do conceito de gênero de texto enquanto instrumento psicológico, apresentamos, a seguir, quatro tópicos que buscam sinalizar a transformação do conceito de gênero em instrumento psicológico, para tentar tornar um pouco mais claras nossas reflexões sobre o desenvolvimento profissional mediado/potencializado pela escrita praxiológica de Alice.

- Qual a influência sobre si mesma desse instrumento psicológico?

Ao tomar para si o conceito de gênero de texto, Alice demonstra uma forma particular de reconfigurá-lo em seu agir, ligando-o diretamente ao gênero que escolheu para seu trabalho. Ao transpor didaticamente o gênero ladainha de capoeira em sua escrita praxiológica, Alice nos dá pistas acerca do conceito de gênero de texto e a influência desse conceito enquanto instrumento psicológico. É na exploração de diferentes elementos constituintes do gênero (sintetizados aqui em termos de estrutura composicional, estilo e conteúdo temático) na transposição didática e, especialmente, na prefiguração de seu agir, que Alice evidencia o quanto o conceito de gênero de texto atua como instrumento psicológico que regula seu agir docente no trabalho com 
PDG. Isso porque, ao fazer as escolhas relacionadas ao que ensinar sobre o gênero e ao elaborar atividades sobre isso, o conceito de gênero de texto atua como instrumento psicológico, intervindo sobre os fenômenos psíquicos relacionados a esse agir. A autorregulação do trabalho de Alice, discutida a seguir, esclarece-nos um pouco mais sobre isso.

- De que forma esse conhecimento implica uma autorregulação do seu trabalho?

O conhecimento do conceito de gênero de texto permite a Alice autorregular seu trabalho, especialmente o didático, pela capacidade de avaliar a dimensão ensinável do gênero que ela aborda em seu PDG. Dito de outra forma: quando Alice determina, em sua prefiguração do trabalho de ensino, o que abordará com os alunos sobre o gênero ladainha de capoeira, ela está autorregulando seu trabalho. A escolha por priorizar, como vimos, o conteúdo temático em detrimento de elementos de sintaxe que pertencem à estrutura composicional do gênero exemplifica essa autorregulação de Alice, que opta por trabalhar, dentre os múltiplos elementos do gênero, aquilo que corresponde às expectativas traçadas por ela em relação ao desenvolvimento e à aprendizagem de seus alunos. Outro exemplo é a grade de avaliação da ladainha de capoeira proposta por Alice. Nela, a professora orienta seu agir - e o dos alunos - para uma avaliação da produção do gênero que leva em conta interlocução, estilo e estrutura composicional. Mesmo que o conceito de gênero de texto possa ir além desses três elementos, o trabalho em sala de aula, orientado pela grade de avaliação, sinaliza para um comportamento claramente autorregulado por Alice, a partir do conceito de gênero de texto.

- Há traços que permitam observar um gesto de autocontrole a partir desse conceito?

Para responder essa indagação, recorremos, neste momento, a algumas palavras de Alice sobre seu próprio PDG:

Hoje, a partir das novas leituras que fiz sobre o trabalho com gêneros, reformularia o projeto, pois utilizei outros gêneros para trabalhar a ladainha. Também pensaria em outras propostas para trabalhar as questões de linguagem e avaliação. (ALICE, 2012). 
Torna-se evidente que Alice, como ela mesma afirma, realizou leituras que orientariam de maneira diferenciada seu agir (futuro) no trabalho com gêneros. Essas leituras certamente ampliaram a compreensão do conceito de gênero de texto de Alice. No entanto, o que a reflexão de Alice sobre sua prática (e, por conseguinte, sua escrita praxiológica) nos revela de mais importante é um gesto de autocontrole (in)consciente de Alice acerca do trabalho com gêneros de texto. A autocrítica presente no segmento temático evidencia sua capacidade de autocontrolar (ou, ao menos, de prever uma forma de autocontrole) de seu agir futuro em termos de ensino de gêneros, pois mostra-se capaz de conceber outras formas de trabalho a partir da ampliação do seu conhecimento sobre o conceito de gênero de texto.

- Por fim, é possível ter acesso a "esquemas de utilização" do conceito em termos de uma expertise profissional no trabalho didático com gêneros de texto?

Ladainha de capoeira, o gênero selecionado por Alice para seu PDG, não é, necessariamente, um "saber sábio", no sentido que Chevallard (1985) dá ao termo, porque não tem relação direta com as descobertas científicas que são alvo de transposição para o sistema escolar. No entanto, é necessário um investimento em transposição didática por parte da professora para que esse gênero seja levado à sala de aula. Esse investimento se orienta claramente por esquemas de utilização do conceito de gênero de texto. Alice, neste PDG, utiliza elementos relacionados ao conceito de gênero de texto e demonstra, com isso, uma expertise profissional.

Ao discutir com seus alunos questões relacionadas à variação linguística, por exemplo, Alice se vale do conceito de gênero a partir da ótica da situação de interação e do estilo que o gênero suporta. Ao trabalhar com as quadrinhas, enfoca a dimensão da infraestrutura textual, notadamente de um dos aspectos sintáticos que compõem o gênero. Ao enfatizar elementos relacionados ao conteúdo temático, apresenta outro esquema de utilização do conceito. Enfim, Alice adequa e adapta o conceito de gênero de texto a serviço da transposição didática que realiza. Talvez essa seja a expertise que ela utiliza nesse PDG, porque escolheu um gênero pouco comum no cenário escolar e que demanda esse modus operandi. O que os dados e a análise até aqui efetuada nos permitem 
afirmar é que o conceito de gênero de texto, em termos bronckartianos ou mesmo bakhtinianos - mesmo não sendo explicitamente discutido por Alice em nenhum momento da sua escrita, foi internalizado pela professora.

Diversos elementos presentes na escrita da professora nos permitiram vislumbrar que Alice não apenas internalizou o conceito como também o reconfigurou em seu agir linguageiro e didático. Essa reconfiguração, ainda que adaptativa, pois Alice fez escolhas sobre o que marcar no trabalho com o conceito de gênero de texto, foi marcada por diferentes índices linguísticos, textuais e discursivos que nos permitem observar o desenvolvimento do conceito em sua escrita e, consequentemente, traços de seu desenvolvimento profissional. Como a própria Alice afirma, em texto reflexivo sobre sua experiência com esse PDG, "não basta a uma formação continuada mostrar o trabalho que pode ser feito" (ALICE, 2012). Parafraseando Alice, é a identificação com o conceito (de gênero de texto), o estudo, a prática e a reflexão sobre a prática que possibilitam ao professor em formação continuada a mudança entre o que já sabe e o que ainda pode (ou quer) saber. É essa mudança que impulsiona o desenvolvimento profissional que vimos marcado na escrita de Alice.

Por fim, não poderíamos deixar de salientar, para além da discussão acerca do desenvolvimento profissional de Alice a partir de sua escrita praxiológica, os efeitos educativos do trabalho de conscientização da diversidade cultural/racial promovido pelo PDG de Alice aqui enfocado, principalmente por ter sido este o fator que influenciou a escolha de um gênero pouco comum nas práticas de ensino-aprendizagem de língua materna. Pensamos ser crucial, noutro espaço-tempo, discutirmos os (possíveis) efeitos que o desenvolvimento profissional de Alice, a elaboração de seu material didático, teve sobre o desenvolvimento (linguístico) de seus alunos. Experiências como essa parecem sinalizar para um espaço de pesquisa acerca do fazer de sala de aula e de estudo sobre gêneros de texto que ainda tem muito a contribuir com as práticas de formação e desenvolvimento de professores de língua portuguesa. 


\section{Referências}

ALICE. Projeto didático de gênero Ladainha de capoeira. São Leopoldo, 2011. Material didático produzido pela autora.

ALICE. Entrevista semiestruturada. 2012.

BAKHTIN, M. Os gêneros do discurso. In: BAKHTIN, M. (Org.). Estética da criação verbal. Tradução Paulo Bezerra. São Paulo: Martins Fontes, 2003. p. 261-306.

BARROS, E. M. D.; RIOS-REGISTRO, E. S. (Orgs.) Experiências com sequências didáticas de gêneros textuais. Campinas: Pontes, 2014.

BOTA, C. Savoirs, textes et apprentissages en milieu universitaire. Pour une analyse socio-discursive de travaux de validation pour le cours. 2011. Tese (Doutorado em Ciências da Educação) - Université de Genève, Genebra, Suíça.

BRASIL. Ministério da Educação e Cultura. Secretaria da Educação Básica. Parâmetros Curriculares Nacionais: língua portuguesa. 3. ed. Brasília: A Secretaria, 1998.

BRONCKART, J. P. Atividade de Linguagem, textos e discursos. Por um interacionismo sócio-discursivo. Tradução Anna R. Machado. Apoio Técnico Péricles Cunha. São Paulo: EDUC, 1999.

BRONCKART, J. P. Atividade de linguagem, discurso e desenvolvimento humano. Campinas: Mercado de Letras, 2006.

BRONCKART, J. P. O agir nos discursos. Campinas: Mercado de Letras, 2008.

BRONCKART, J. P. Um retorno necessário à questão do desenvolvimento. In: BUENO, L.; LOPES, M. A. T.; CRISTÓVÃO, V. L. L. (Org.). Gêneros textuais e formação inicial: uma homenagem à Malu Matêncio. Campinas: Mercado de Letras, 2013. p. 85-107. 
CARNIN, A. Na escrita do professor, um caminho possivel para a análise do (seu) desenvolvimento profissional. 2015. Tese (Doutorado em Linguística Aplicada) Universidade do Vale do Rio dos Sinos, São Leopoldo.

CHEVALLARD, Y. La transposition didactique. Grenoble: La Pensée Sauvage, 1985.

CRESWELL, J. W. W. Projeto de pesquisa: métodos qualitativo, quantitativo e misto. 2. ed. Porto Alegre: Bookman, 2010.

DOLZ, J.; NOVERRAZ, M.; SCHNEUWLY, B. Sequências didáticas para o oral e a escrita: apresentação de um procedimento. In: DOLZ, J.; SCHNEUWLY, B. Gêneros orais e escritos na escola. Tradução e Organização Roxane Rojo e Glaís Sales Cordeiro. Campinas: Mercado de Letras, 2004. p. 95-128.

FÉRREZ, R. S. Amanhecer esmeralda. Rio de Janeiro: Objetiva, 2005.

FRIEDRICH, J. Lev Vigotski: mediação, aprendizagem e desenvolvimento. Campinas: Mercado de Letras, 2012.

GUIMARÃES, A. M. M.; CARNIN, A. "E daí...” ou: sobre os passos seguintes num caminho de trabalho cooperativo. In: GUIMARÃES, A. M. M.; KERSCH, D. F. (Org.). Caminhos da construção: projetos didáticos de gênero no domínio do argumentar. Campinas: Mercado de Letras, 2014. p. 39-50.

GUIMARÃES, A. M. M.; KERSCH, D. F. (Org.). Caminhos da construção: projetos didáticos de gênero no domínio do argumentar. Campinas: Mercado de Letras, 2014. GUIMARÃES, A. M. M.; KERSCH, D. F. (Org.). Caminhos da construção: projetos didáticos de gênero na sala de aula de língua portuguesa. Campinas: Mercado de Letras, 2012.

GUIMARÃES, A. M. M.; KERSCH, D. F. (Org.). Caminhos da construção: projetos didáticos de gênero no domínio do argumentar. Campinas: Mercado de Letras, 2014.

MACHADO, A. R.; LOUSADA, E. G. A apropriação de gêneros textuais pelo professor: em direção ao desenvolvimento pessoal e à evolução do 
“métier”. Linguagem em (Dis)curso, Palhoça, v. 10, n. 3, p. 619-633, set./dez. 2010.

PEREIRA, R. C. M. Ações de linguagem e prática docente: desafios e avanços na formação continuada. In: PEREIRA, R. C. M. (Org.). Ações de linguagem: da formação continuada à sala de aula. João Pessoa: Editora Universitária da UFPB, 2010. p. 17-33.

REUTER, Y. Statut et usages de la notion de genre en didactique(s): retour sur quelques propositions. Pratiques, Paris, n. 157/158, p. 153-164, jun. 2013.

VIGOTSKI, L. S. A construção do pensamento e da linguagem. São Paulo: Martins Fontes, 2009 [1934].

Recebido em: 02/06/2015 Aceito: 23/11/2015 